\title{
Lutzomyia aldafalcaoae sp. n. a New Species of Phlebotominae (Diptera: Psychodidae) from Mato Grosso do Sul, Brazil
}

\author{
Soraya Oliveira Santos, José Dilermando Andrade Filho*/+, \\ Michael R Honer**
}

\begin{abstract}
Fundação Nacional de Saúde, Campo Grande, MS, Brasil *Laboratório de Leishmanioses, Centro de Pesquisas René Rachou-Fiocruz, Av. Augusto de Lima 1715, 30190-002 Belo Horizonte, MG, Brasil

**Centro de Ciências Biológicas e da Saúde, UFMS, Campo Grande, MS, Brasil
\end{abstract}

A new sand fly species, Lutzomia aldafalcaoae is described from males collected in Vila Trindade, an urban district in Aquidauana county, State of Mato Grosso do Sul, Brazil, in October 1996. Taxonomic remarks and a description of the new species is presented.

Key words: Lutzomyia aldafalcaoae sp. n. - Phlebotominae - sand fly - Diptera - Psychodidae - taxonomy -

Mato Grosso do Sul - Brazil

In October 1996 an entomological survey was carried out in the town of Aquidauana, State of Mato Grosso do Sul, an area of endemic cutaneous leishmaniasis (Funasa-MS) and where the first notification of American visceral leishmaniasis was registered. Aquidauana is located in the Pantanal region at $21 \mathrm{~K} 0626262$ and UTM 7735321 . The climate is hot and wet; the vegetation is scrub, and the Bodoquena range is close. During the field study eleven species were identified: Lutzomyia longipalpis (Lutz \& Neiva), Lutzomyia cruzi (Mangabeira), Lutzomyia shannoni (Dyar), Lutzomyia whitmani (Antunes \& Coutinho), Lutzomyia termitophila Martins Falcão \& Silva, Lutzomyia forattinii Galati Rego Nunes \& Teruya, Lutzomyia lenti (Mangabeira), Lutzomyia hermanlenti Martins Silva \& Falcão, Lutzomyia sallesi (Galvão \& Coutinho), Brumptomyia brumpti (Larrousse), Brumptomyia sp. Three specimens of an undescribed species were also found. These had been captured inside a house in the urban district of Vila Trindade using miniature light traps (CDC).

The present description is based on the characters proposed by the CIPA Group (1991) and Galati (1995).

\footnotetext{
This work was supported by Fundação Nacional de Saúde, Fiocruz and Opas (grant-FI/CSP/0798/99).

${ }^{+}$Fundep scholarship and corresponding author. Fax: +55-31-3295.3566. E-mail: jandrade@cpqrr.fiocruz.br Received 6 November 2000

Accepted 8 Febuary 2001
}

Lutzomyia aldafalcaoae sp. $\mathrm{n}$.

(Figs 1 A-H; 2 I-O)

Male: holotype (measurements are in $\mathrm{mm}$ ). Sand fly of medium size. Length 2.5 . General coloration is light brown, including the pleura.

Head: $0.231(0.239 ; n=3)$ excluding clypeus, this with a length of $0.138(0.141 ; \mathrm{n}=3)$. Ratio head/ clypeus 1.67:1. Epipharynx-labrum (LE) 0.176 $(0.173 ; \mathrm{n}=3)$. Lengths of palpomeres: $1-0.024$ $(0.027 ; \mathrm{n}=3), 2-0.090(0.092 ; \mathrm{n}=3), 3-0.131$ $(0.123 ; \mathrm{n}=3), 4-0.100(0.093 ; \mathrm{n}=3), 5-0.197$ $(0.217 ; \mathrm{n}=3)$. Palpal formula 1.2.4.3.5 with palpomere 5th smaller than 3rd+4th and $2 n d+3 r d$. In another two specimens the palpal formula is 1.4.2.3.5. One of them, the 5th palpomere is longer than $3 \mathrm{rd}+4$ th with an approximate value of the 2 nd +3 rd+4th. The Newstead spines are present on the 2 nd and 3 rd palpomere. Antennae with the first flagellomere length: AIII-0.211 $(0.206 ; \mathrm{n}=3)$; AIV-0.114 (0.109; $\mathrm{n}=3)$; AV-0.117 (0.110; $\mathrm{n}=$ $3)$. The ratio AXVI/AXV $0.84: 1$ and AIII/LE 1.20:1. Ascoidal formula: AIII-AXV 2, AXVI 0. The ascoids on AIV are simple without proximal prolongation, the apex reaches the subsequent segment. Papillae are present on AIII, AIV, AV, AXII, AXIII, AXIV, AXV, and AXVI. Ventro-cervical sensillae are present in the cervix.

Thorax: notum and pleura light brown. Middle and hind femur in the paratype measure 0.653 and 0.738 , respectively. Wing length $1.632(1.696 ; n$ $=2)$ and $0.454(0.454 ; \mathrm{n}=3)$ of the maximum width. Lengths of wing sections: R5-1.050 (1.097; $\mathrm{n}=3)$; alfa-0.341 (0.308; $\mathrm{n}=3)$; beta-0.213 (0.241; $\mathrm{n}=3)$; gama-0.241 $(0.251 ; \mathrm{n}=3)$ and delta- 0.085 $(0.047 ; \mathrm{n}=3)$. Setae are present on the katerpisternum. 
Abdomen: presence of tergal papillae only on the 5 th and 6 th tergites. Coxite 0.342 long, maximum width $0.114(0.111 ; \mathrm{n}=3)$ with one basal tuft of 10 to 12 and a slack tuft with six bristles implanted in the middle of the internal face. Style measuring $0.207(0.200 ; \mathrm{n}=3)$ with four spines, one terminal, one subterminal, one external intermediary and one internal basal. Subterminal seta present. Paramere $0.204(0.212 ; n=3)$ length, presence of ventral process in the form of a tooth, in the middle of the structure and having the middle third covered by bristles. Lateral lobe highly developed with $0.442(0.443 ; n=3)$ length and maximum width
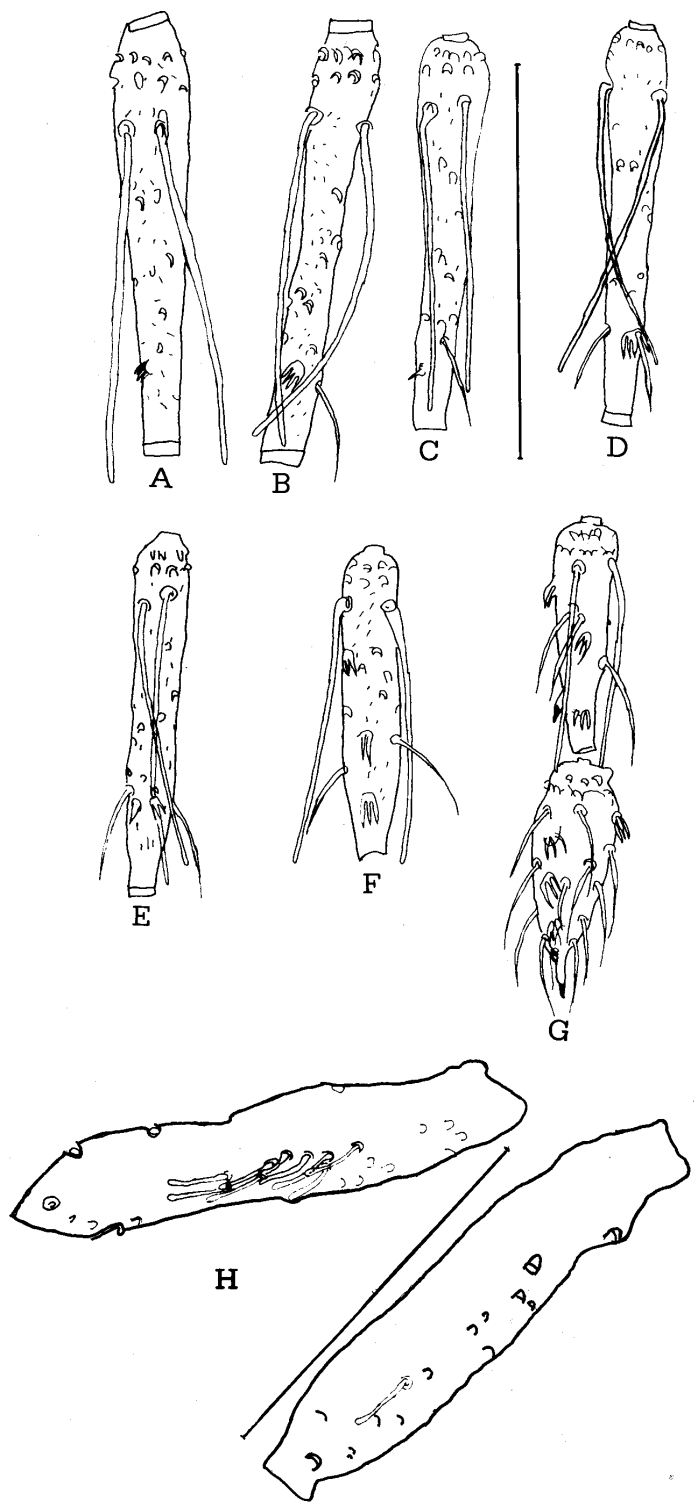

Fig. 1: Lutzomyia aldafalcaoao sp. n. - A: AIV; B: AV; C: AXI; D: AXII; E: AXIII; F: AXIV; G: AXV and AXVI; H: 1st, 2nd and 3rd palpomeres. Bar: $100 \mu \mathrm{m}$
$0.035(0.038 ; \mathrm{n}=3)$, the apex appears slender with from four to seven spatulate setae. Ratio between lateral lobe/coxite 1.29:1. Aedeagus well sclerotized with the extremity modified in the form of the nipple of a feeding bottle. Genital pump 0.152 $(0.162 ; \mathrm{n}=3)$ long. Genital filaments $0.383(0.379$; $\mathrm{n}=3$ ) long being $2.52 \mathrm{X}$ the length of the pump. The apex of the genital filament is modified and bifurcated, reminding a champagne glass.

Type: holotype and paratype males captured with CDC (miniature lights traps) in Vila Trindade, urban district of the municipality of Aquidauana, Mato Grosso do Sul, on 12 October 1996 (F Portes col.) and another specimen were captured in the same local on 13 December 1996 (F Portes col.). The material is deposited in the collection of sand flies at the Centro de Pesquisas René RachouFiocruz, Belo Horizonte, Minas Gerais.

The name Lutzomyia aldafalcaoae sp. $\mathrm{n}$. is given in honour of the researcher Alda Lima Falcão, Centro de Pesquisas René Rachou-Fiocruz, Belo Horizonte, who has made important contributions to the study of these insects.

\section{TAXONOMIC DISCUSSION}

The presence of spatulate setae on the lateral lobe, coxite with a basal setae group, style with four spines and subterminal seta, simple paramere and aedeagus fit $L$. aldafalcaoae sp. n. in the subgenus Evandromyia Mangabeira, in the infraspinosa series by Young and Duncan (1994). Eleven species are included in this subgenus, nine in the infraspinosa series (Young \& Arias 1977). L. aldafalcaoae sp. n. can easily be distinguished from all described species: Lutzomyia infraspinosa (Mangabeira), Lutzomyia begonae (Ortiz \& Torres), Lutzomyia brachyphalla (Mangabeira), Lutzomyia cerqueirai (Causey \& Damasceno) and Lutzomyia tarapacaensis Le Pont Torrez-Espejo $\&$ Galati, because these species show the paramere bifurcate, while the new species is simple, differing also from Lutzomyia inpai Young \& Arias, Lutzomyia bourrouli (Barretto \& Coutinho), Lutzomyia pinottii (Damasceno \& Arouck) and Lutzomyia sipani Fernandez Carbajal Alexander $\&$ Need due to the aspect of the apex of the genital filaments, which has its point modified in the shape of a champagne glass; to the paramere, which has a ventral process in the shape of a tooth and a tuft of bristles on the coxite which has fewer setae than other species. L. aldafalcaoae sp. n. differs from all the species of the subgenus, by the number of the spatulate setae on the lateral lobe numbering from of four to seven, while on other species it varies from zero to four and, further still, to the appearance of the aedeagus which is modified into the shape of the nipple of a feeding bottle. 

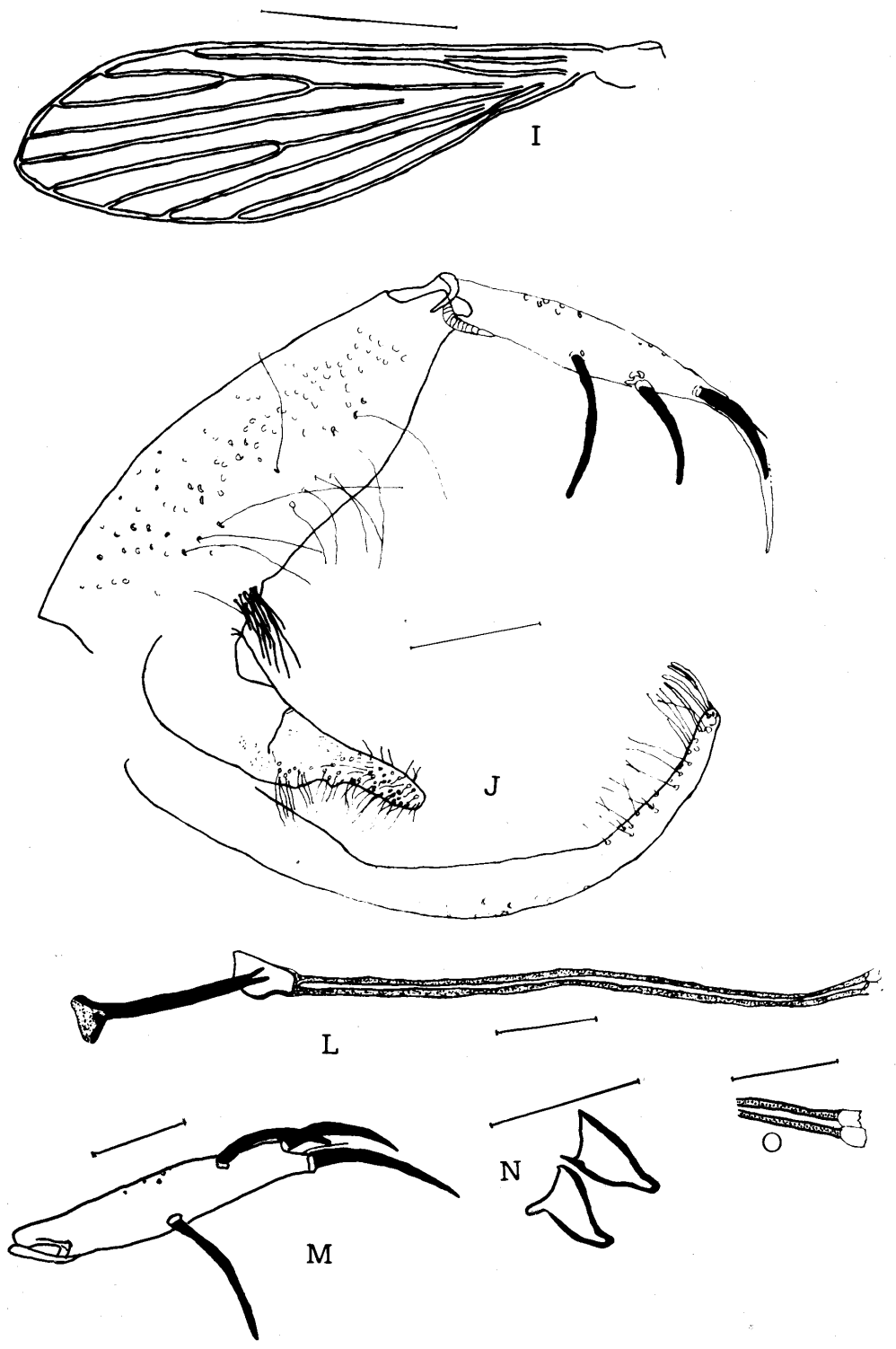

Fig. 2: Lutzomyia aldafalcaoae sp. n. - I: wing; Bar: 500 um; J: genitalia; L: genital pump and filaments; M: style; N: aedeagus; O: apex of the genital filament. Bar: $100 \mu \mathrm{m}$.

Following Galati's classification (1995) the AIII reduction, the presence of Newstead spines on the 2nd palpal segment, the lateral lobe with acute apex and the absence of papillae on the 7th abdominal tergite, classify the new species as belonging to the genus Evandromyia subgenus Aldamyia. L. aldafalcaoae sp. n. can be distinguished from other species of this subgenus by the presence of spatulate setae on the lateral lobe. In this subgenus the species more resembling are Lutzomyia walkeri (Newstead) and Lutzomyia dubitans (Sherlock), but can distinguished by length of filament genital, that is bigger in $L$. aldafalcaoe sp. $\mathrm{n}$. and by aspect of paramere and aedeagus.

We will not put it in either of these two classifications until the other sex is known, which will permit us to give it the correct zoological status.

\section{ACKNOWLEDGEMENTS}

To Dr Eunice A Bianchi Galati for her help with the figure of the sand fly, to Dr Aroldo Galvão, coordinator of the entomology team of the Funasa-Mato Grosso do Sul for his collaboration with field and laboratory work. 


\section{REFERENCES}

CIPA Group. Bermudes H, Dedet JP, Falcão AL, Feliciangelli D, Ferro C, Galati EAB, Gomes EL, Herrero MV, Hervas D, Lebbe J, Morales A, Oguzuku E, Perez E, Rangel EF, Sherlock IA, Torres M, Vignes R, Wolff M 1991. Proposition of a standard description for phlebotomine sand flies. Parasitologia 33 (Supl.): 127-135.

Galati EAB 1995. Phylogenetic sistematics of Phlebotominae (Diptera: Psychodidae) with empha- sis on American groups. Bol Dir Malariol Saneam Amb 35 (Supl. 1): 133-142.

Young DG, Arias JR 1977. Lutzomyia sand flies in the subgenus Evandromyia Mangabeira with descriptions of a new species from Brazil (Diptera: Psychodidae). Acta Amazonica 7: 59-70.

Young DG, Duncan MA 1994. Guide to the identification and geographic distribution of Lutzomyia sand flies in the Mexico, the West Indies, Central and the South America (Diptera: Psychodidae). Mem Am Entomol Inst 54: 303-324. 